\title{
Effect of whitening toothpaste on titanium and titanium alloy surfaces
}

\section{Adriana Cláudia Lapria Faria Angelo Rafael de Vito Bordin Vinícius Pedrazzi Renata Cristina Silveira Rodrigues Ricardo Faria Ribeiro}

Department of Dental Materials and Prosthodontics, School of Dentistry of Ribeirão Preto, University of São Paulo USP, Ribeirão Preto, SP, Brazil.
Declaration of Interests: The authors certify that they have no commercial or associative interest that represents a conflict of interest in connection with the manuscript.

Corresponding Author:

Vinícius Pedrazzi

E-mail:pedrazzi@forp.usp.br

Submitted: Feb 17, 2012

Accepted for publication: May 04, 2012

Last revision: May 22, 2012
Abstract: Dental implants have increased the use of titanium and titanium alloys in prosthetic applications. Whitening toothpastes with peroxides are available for patients with high aesthetic requirements, but the effect of whitening toothpastes on titanium surfaces is not yet known, although titanium is prone to fluoride ion attack. Thus, the aim of the present study was to compare Ti-5Ta alloy to cp Ti after toothbrushing with whitening and conventional toothpastes. Ti-5Ta (\%wt) alloy was melted in an arc melting furnace and compared with cp Ti. Disks and toothbrush heads were embedded in PVC rings to be mounted onto a toothbrushing test apparatus. A total of 260,000 cycles were carried out at 250 cycles/minute under a load of $5 \mathrm{~N}$ on samples immersed in toothpaste slurries. Surface roughness and Vickers microhardness were evaluated before and after toothbrushing. One sample of each material/ toothpaste was analyzed by Scanning Electron Microscopy (SEM) and compared with a sample that had not been submitted to toothbrushing. Surface roughness increased significantly after toothbrushing, but no differences were noted after toothbrushing with different toothpastes. Toothbrushing did not significantly affect sample microhardness. The results suggest that toothpastes that contain and those that do not contain peroxides in their composition have different effects on cp $\mathrm{Ti}$ and $\mathrm{Ti}-5 \mathrm{Ta}$ surfaces. Although no significant difference was noted in the microhardness and roughness of the surfaces brushed with different toothpastes, both toothpastes increased roughness after toothbrushing.

Descriptors: Titanium; Toothbrushing; Tooth Bleaching Agents.

\section{Introduction}

Commercially pure titanium (cp Ti) has been used for dental prosthesis frameworks because of its many advantages, including biocompatibility, corrosion resistance, low density and mechanical properties. ${ }^{1}$ However, some inherent casting problems have limited its routine use ${ }^{2}$ and prompted the search for alternative titanium alloys.

The corrosion resistance, biocompatibility, mechanical properties and wear resistance of Ti-Ta (titanium-tantalum) alloys have been studied. ${ }^{3-6}$ Interest in the Ti-Ta alloy has increased mainly because the $\mathrm{Ta}_{2} \mathrm{O}_{5}$ (tantalum oxide) passive layer created at the Ti-Ta alloy surface is more stable than the $\mathrm{TiO}_{2}$ (titanium oxide) found at the cp Ti surface, which improves corrosion resistance and biocompatibility.

Some authors have noted that the fluoride added to toothpaste ex- 
erts a corrosive effect by destroying the $\mathrm{TiO}_{2}$ passive layer on cp Ti. ${ }^{7,8}$ Additionally, toothpaste abrasives and toothbrush bristles may deteriorate tooth and restorative material surfaces by producing superficial grooves. ${ }^{9-12}$

The recent surge in the search for bleaching treatments, driven by high aesthetic requirements, has increased the use of hydrogen or carbamide peroxides. Several studies have investigated the effect of bleaching agents on the surface of different restorative materials, such as amalgam, $\mathrm{Ni}-\mathrm{Cr}$ alloys, composite resins, glass ionomer and feldspathic porcelain. ${ }^{13-15}$ Bleaching agents have been shown to decrease the microhardness of feldspathic porcelain and increase that of light-cured modified glass ionomer cements through erosion, whereas composite resin reacted differently depending on the bleaching agent used. ${ }^{13}$ The surface roughness of microfilled composite resin and modified glass ionomer cements increased after 2 weeks of bleaching agent use, presenting surface porosities and cracks at the surface of composite resin and cracks in glass ionomer cements. Conversely, feldspathic porcelain was not affected by bleaching agents. ${ }^{14}$ Additionally, some bleaching agents may cause corrosion of nonpolished amalgam samples and nickel-chromium specimens by an increased release of amalgam components from amalgam samples. ${ }^{15}$ However, the effects of bleaching agents and whitening toothpastes on titanium surfaces are not known.

Because the clinical use of titanium frameworks has increased owing to advances in implantology and peroxide-containing whitening toothpastes released on the market, it has become important to study the hypothesis that whitening toothpaste interferes with $\mathrm{cp} \mathrm{Ti}$ and alternative $\mathrm{Ti}-5 \mathrm{Ta}$ alloy surfaces differently than conventional toothpaste. Thus, the aim of the present study was to evaluate the effect of whitening toothpaste on the cp $\mathrm{Ti}$ and alternative $\mathrm{Ti}-5 \mathrm{Ta}$ alloy surface compared with conventional toothpaste.

\section{Methodology}

The materials used in the present study were experimental titanium-tantalum $\mathrm{Ti}-5 \mathrm{Ta}$ (in wt $\%$ ) alloy and the grade $2 \mathrm{cp} \mathrm{Ti}$ as the control (Table 1 ).

Experimental alloy was produced from sheets of raw titanium and tantalum. Melting was performed in an arc melting furnace under an argon atmosphere. Prior to melting, the melting chamber was emptied and purged with argon. An argon pressure of $1 \mathrm{~atm}$ was maintained during melting. Appropriate quantities of $\mathrm{Ti}$ (titanium) and $\mathrm{Ta}$ (tantalum) were melted in a U-shaped copper hearth using a tungsten electrode. The ingots were remelted ten times to improve chemical homogeneity. A high-purity argon gas was used.

Disks measuring $13 \mathrm{~mm}$ in diameter and $4 \mathrm{~mm}$ in thickness were obtained from wax patterns that were invested with Rematitan Plus (Dentaurum, Ispringen, Germany) and cast from $\mathrm{Ti}-5 \mathrm{Ta}$ and $\mathrm{cp} \mathrm{Ti}$ by plasma. The melting was performed in a Discovery Plasma casting machine (EDG Equipamentos e Controles Ltda., São Carlos, Brazil) by arc melting Table 1 - Materials and supplies
used in the study.

\begin{tabular}{c|c|c|c}
\hline Materials/Supplies & Type & Lot & Manufacturer \\
\hline Titanium alloy: Ti-5Ta & Experimental* & $\# 001$ & $\begin{array}{c}\text { Muller Metais Indústria e Com. Ltda., } \\
\text { Barueri, Brazil }\end{array}$ \\
\hline Titanium: grade 2 cp Ti & $100-102-50$ & $\begin{array}{c}\text { Tritan, Dentaurum, Ispringen, } \\
\text { Germany }\end{array}$ \\
\hline Oral B Indicator Plus & $\begin{array}{c}35 \text { Soft bristle } \\
\text { toothbrushes }\end{array}$ & 99363971 & Procter \& Gamble, Manaus, Brazil \\
\hline Rembrandt Deeply White & $\begin{array}{c}\text { (REM) Peroxide } \\
\text { dentifrice }\end{array}$ & 0450A & Johnson \& Johnson, Skillman, USA \\
\hline Sorriso Dentes Brancos & (SOR) & 1003BR122A & $\begin{array}{c}\text { Colgate-Palmolive, São Bernardo do } \\
\text { Campo, Brazil }\end{array}$ \\
\hline
\end{tabular}

${ }^{*} \mathrm{Ti}$ (99.9\% in purity, Muller Metais Indústria e Com. Ltda., Barueri, Brazil) and Ta ( $99.9 \%$ in purity, SigmaAldrich, St. Lovis, USA). 
in a vacuum and argon inert atmosphere with injection of the alloy/metal into the mold by vacuum pressure. After casting, the samples were removed from the cast and the airborne-particle abraded with aluminum oxide particles $\left(80 \mathrm{psi}=5.62 \mathrm{kgf} / \mathrm{cm}^{2}\right)$.

Sixteen samples of each material were obtained and subdivided into two groups according to the toothpaste to be tested. For the toothbrushing tests, the samples were embedded in PVC rings using autopolymerizing resin and mounted onto the toothbrushing test apparatus. The samples were then polished with sequential silicon carbide papers (320, 400, 600, 1200, 1500 and 2000 grid). Before the tests, the samples were cleaned in an ultrasonic bath, immersed in isopropyl alcohol (5 minutes) and then in distilled water (5 minutes).

Oral B Indicator Plus soft bristle toothbrushes were cut to separate their heads and handles, and the toothbrush heads were embedded in PVC rings using autopolymerizing resin to prepare for mounting onto the toothbrushing test apparatus, which was developed in the Department of Dental Materials and Prosthodontics at Ribeirão Preto Dental School, University of São Paulo. The toothbrushes were mounted on at the vertical arm of the toothbrush test apparatus under a load of approximately $5 \mathrm{~N}$ while the disks were mounted on an orifice present in a box that caused a sliding motion as it moved horizontally. The grinding distance was $10 \mathrm{~mm}$, and each entire sequence of motion constituted one cycle. A total of 260,000 cycles were carried out at a speed of 250 cycles/minute ${ }^{16}$ for each set of samples. Testing represented 2 minutes of toothbrushing twice a day for 2 years. ${ }^{17}$

For toothbrushing tests, toothbrushes contacted disks immersed in toothpaste slurry (150 g toothpaste and $150 \mathrm{~mL}$ deionized water) in a proportion determined in a previous experiment. The toothpastes used were Rembrandt Deeply White + Peroxide (REM) and Sorriso Dentes Brancos (SOR). Throughout the test, the toothpaste slurry was shaken to maintain homogeneity. The $\mathrm{pH}$ of each solution was evaluated at the beginning and end of the test using a digital $\mathrm{pH}$ meter (Bel, Bel Engineering S.r.l., Monza, Italy).

After the toothbrushing tests, the samples were again cleaned in an ultrasonic bath, immersed in isopropyl alcohol (5 minutes) and then in distilled water (5 minutes) to completely remove slurry residue.

Surface roughness was evaluated before and after toothbrushing tests using a roughness tester (SJ201P, Mitutoyo, Kanagawa, Japan) with a $300 \mu \mathrm{m}$ resolution, $0.5 \mathrm{~mm} / \mathrm{s}$ speed and $0.8 \mathrm{~mm}$ cut-off. Three measures, expressed as Ra, were performed for the sample, and the arithmetic mean of these measures was considered the surface roughness of the sample.

The surface Vickers microhardness of $\mathrm{cp} \mathrm{Ti}$ and Ti-5Ta was evaluated before and after toothbrushing tests. The microhardness was measured using a microhardness tester (HMV-2 Shimadzu Corp., Kyoto, Japan) at a load of $19.614 \mathrm{~N}$ applied for $20 \mathrm{~s}$. The microhardness values were obtained at five sites that had been submitted to toothbrushing, and the arithmetic mean of the measures was determined.

To evaluate the surfaces of samples submitted to toothbrushing, one sample of each material/toothpaste was analyzed by scanning electron microscopy (SEM) and compared to a sample that had not been submitted to toothbrushing.

To evaluate the effect of toothbrushing and toothpaste on the materials' surfaces, a statistical analysis was performed using a mixed linear model, which is a generalization of the standard linear model (ANOVA). This model is used in the analysis of data in which the responses of the same specimen are grouped and the assumption of independence among observations in the same group is not adequate. $^{18}$ To use this model, errors must have a normal distribution with a mean of zero and constant variance. Differences were considered significant when $\mathrm{p}<0.05$.

\section{Results}

Surface roughness results are presented in Table 2. The surface roughness of samples increased significantly after toothbrushing $(\mathrm{p}<0.05)$, but no differences were noted between cp $\mathrm{Ti}$ and $\mathrm{Ti}-5 \mathrm{Ta}$ brushed with REM or SOR $(\mathrm{p}=0.320)$.

The Vickers microhardness results are presented in Table 3. Toothbrushing did not significantly affect sample microhardness $(p=0.056)$, and no dif- 

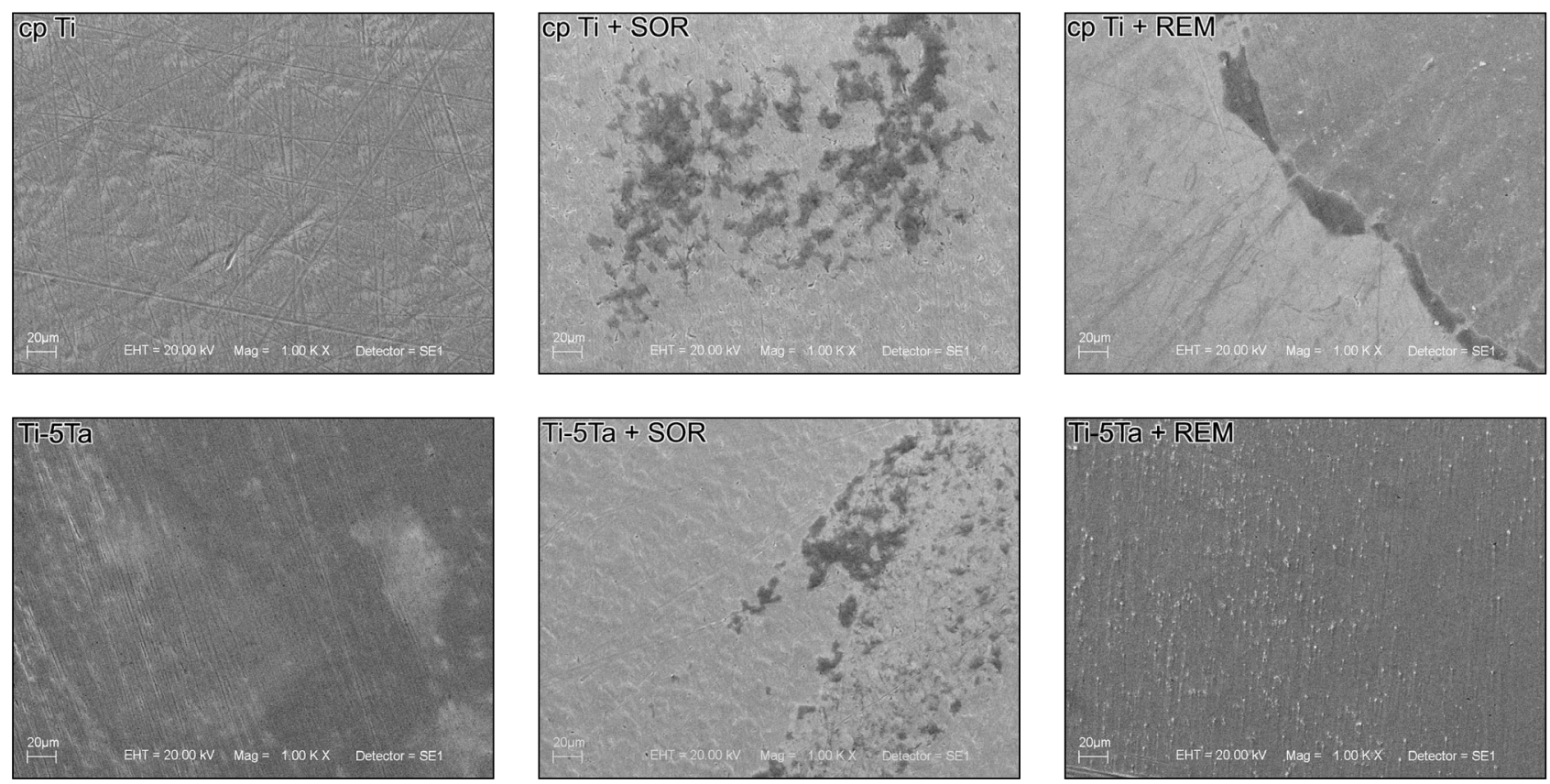

Figure 1 - Scanning electron micrographs of sample surface before toothbrushing: $\mathbf{c p}$ Ti and Ti-5Ta; after toothbrushing with SOR: $\mathbf{c p}$ Ti + SOR and Ti-5Ta + SOR; and after toothbrushing with REM: cp Ti + REM and Ti-5Ta + REM (Original magnification of $1000 \times)$.

Table 2 - Surface roughness data $(\mu \mathrm{m})$ of $\mathrm{cp}$ Ti and Ti-5Ta before and after toothbrushing using SOR and REM slurries. Data are presented as the mean (standard deviation).

\begin{tabular}{c|c|c|c|c}
\hline \multirow{2}{*}{} & \multicolumn{2}{|c|}{ Before toothbrushing } & \multicolumn{2}{c}{ After toothbrushing } \\
\cline { 2 - 5 } & SOR & REM & SOR & REM \\
\hline \multirow{2}{*}{$\mathrm{cp} \mathrm{Ti}$} & 0.14 & 0.16 & 0.21 & 0.20 \\
& $(0.02)$ & $(0.03)$ & $(0.06)$ & $(0.09)$ \\
\hline \multirow{2}{*}{$\mathrm{Ti}-5 \mathrm{Ta}$} & 0.13 & 0.13 & 0.18 & 0.18 \\
& $(0.01)$ & $(0.01)$ & $(0.06)$ & $(0.06)$ \\
\hline
\end{tabular}

ference was noted among cp $\mathrm{Ti}$ and $\mathrm{Ti}-5 \mathrm{Ta}$ microhardness brushed with REM or SOR ( $\mathrm{p}=0.331$ ).

Images of $\mathrm{cp} \mathrm{Ti}$ and $\mathrm{Ti}-5 \mathrm{Ta}$ surfaces before and after toothbrushing are presented in Figure 1.

The $\mathrm{pH}$ evaluation at the beginning and end of the toothbrushing assay is presented in Table 4.

\section{Discussion}

In the present study, a Ti-5Ta alloy was used as an alternative to $\mathrm{cp} \mathrm{Ti}$ because its surface presents a passive layer of $\mathrm{Ta}_{2} \mathrm{O}_{5}$, which is less vulnerable to damage than the $\mathrm{TiO}_{2}$ present at cp Ti surface. ${ }^{5}$ As the chemical action of fluoridated toothpastes is known to have a corrosive effect on titanium surfac-
Table 3 - Vickers microhardness data (VHN) of $\mathrm{cp} T i$ and Ti-5Ta before and after toothbrushing using SOR and REM slurries. Data are presented as the mean (standard deviation).

\begin{tabular}{c|c|c|c|c}
\hline \multirow{2}{*}{} & \multicolumn{2}{|c|}{ Before toothbrushing } & \multicolumn{2}{c}{ After toothbrushing } \\
\cline { 2 - 5 } & SOR & REM & SOR & REM \\
\hline \multirow{2}{*}{$\mathrm{cP} \mathrm{Ti}$} & 245.8 & 209.5 & 210.3 & 204.4 \\
& $(79.5)$ & $(44.2)$ & $(52.2)$ & $(55.7)$ \\
\hline \multirow{2}{*}{ Ti-5Ta } & 208.5 & 236.2 & 174.4 & 198.3 \\
& $(54.8)$ & $(83.8)$ & $(47.1)$ & $(70.8)$ \\
\hline
\end{tabular}

es by destroying the passive layer, which increases ion release, ${ }^{7,8}$ an alternative alloy, which has a passive layer more resistant than that of $\mathrm{cp} \mathrm{Ti}$, would be interesting to study. However, no differences between cp Ti and Ti-5Ta microhardness and roughness were noted after toothbrushing.

According to Hossain et al., ${ }^{9,10}$ the interaction between titanium surface and abrasives are $\mathrm{pH}$ dependent. Similarly, Nakagawa et al. ${ }^{19}$ reported that the corrosion process on the titanium surface is dependent on fluoride ion concentration and solution $\mathrm{pH}$ and concluded that greater fluoride concentrations and lower $\mathrm{pH}$ increase the corrosion on titani- 
Table 4 - $\mathrm{pH}$ of slurries at the beginning and end of toothbrushing tests.

\begin{tabular}{c|c|c|c}
\hline \multirow{2}{*}{$\begin{array}{c}\text { Alloy/ } \\
\text { toothpaste }\end{array}$} & \multirow{2}{*}{ Test } & \multicolumn{2}{|c}{$\mathrm{pH}$ evaluation } \\
\cline { 3 - 4 } & & Before toothbrushing & After toothbrushing \\
\hline \multirow{2}{*}{$\mathrm{cP} \mathrm{Ti} /$ SOR } & 1 & 9.65 & 9.72 \\
\cline { 2 - 4 } & 2 & 9.64 & 9.51 \\
\hline \multirow{2}{*}{$\mathrm{cP} \mathrm{Ti} /$ REM } & 1 & 5.89 & 5.87 \\
\cline { 2 - 4 } & 2 & 5.83 & 5.81 \\
\hline \multirow{2}{*}{ Ti-5Ta / SOR } & 1 & 9.81 & 9.96 \\
\cline { 2 - 4 } & 2 & 9.78 & 9.89 \\
\hline \multirow{2}{*}{ Ti-5Ta / REM } & 1 & 5.42 & 5.28 \\
\cline { 2 - 4 } & 2 & 5.80 & 5.84 \\
\hline
\end{tabular}

um surfaces. In the present study, a large difference in the $\mathrm{pH}$ of slurries prepared with different toothpastes was noted, even though the fluoride concentration was nearly identical (SOR: $1450 \mathrm{ppmF} \times$ REM: 1166 ppmF). The REM slurry had an acidic $\mathrm{pH}$ with higher stability, which is probably due to its specific ingredients, such as the effective thickening agent and the peroxide, whereas the SOR had an alkaline $\mathrm{pH}$. Nevertheless, this difference did not affect microhardness and roughness among the samples after toothbrushing.

Titanium dissolution causes surface roughness with cracks due to passive layer breakage. ${ }^{20} \mathrm{Al}-$ though roughness was not significantly different after toothbrushing, SEM images suggest that $\mathrm{cp} \mathrm{Ti}$ and Ti-5Ta surfaces are different after toothbrushing with REM and SOR. Sample surfaces before toothbrushing present grooves remaining from the polishing. After toothbrushing, those remaining grooves partially disappear, most likely because abrasives in the toothpaste polished the metal surface. The comparison of samples brushed with SOR and REM revealed fewer grooves after toothbrushing with REM, which suggests greater surface wear compared to those brushed with SOR. This difference can be partially attributed to the abrasives in the REM (silica and aluminum hydroxide) and SOR (calcium carbonate) toothpastes. Additionally, it is possible that calcium disodium EDTA and urea peroxide lowered the $\mathrm{pH}$ of the REM slurry, thus favoring greater surface attack once small pittings form.
This difference is noted for both cp $\mathrm{Ti}$ and $\mathrm{Ti}-5 \mathrm{Ta}$ but is more evident for Ti-5Ta, most likely because the $\beta$-phase present in the Ti-5Ta alloy increases its ductility. ${ }^{6}$

Additionally, the possible consequences of peroxide-containing REM toothpaste on titanium surfaces are not yet known. Some studies argue that the microhardness of restorative materials such as feldspathic porcelain decreases after bleaching, ${ }^{13}$ whereas that of other restorative materials such as glass ionomer cements increases and that of resin-modified glass ionomer cements increases or decreases depending on the commercial brand. In the present study, the microhardness of the materials brushed with different toothpastes was similar before and after toothbrushing.

In relation to surface roughness, some studies show that the roughness of restorative materials, such as composite resins, glass ionomer cements, feldspathic porcelain and amalgam, may or may not be affected after contact with bleaching agents ${ }^{14,15}$ and that the change in roughness is related to the material and time of exposure to the product. Nevertheless, there are no studies in the literature that evaluate the effect of whitening toothpastes on $\mathrm{cp} \mathrm{Ti}$ and titanium alloy surfaces. In the present study, an increase in roughness was noted after toothbrushing, but no difference between the materials was noted after toothbrushing with the different toothpastes.

One limitation of the present study is related to the load applied throughout the toothbrushing assays. Whereas other studies used a load of $200 \mathrm{~g}^{16,17}$ or $375 \mathrm{~g},{ }^{21}$ the present study applied a $500 \mathrm{~g}(5 \mathrm{~N})$ load because of an equipment limitation.

The results of the present study did not permit the indication of certain toothpastes for patients treated with titanium implants, but it is known that carbamide peroxide increases oxidation, corrosion and dissolution of amalgam surfaces, which increases ion release. ${ }^{22}$

According to Siirilä e Könönen, ${ }^{7}$ titanium corrosion in the presence of a solution with a high fluoride concentration is superficial and transitional because the passive layer created on the titanium surface reassembles quickly, and corrosion products and 
fluoride ions will be eliminated and diluted in the natural oral environment. However, some authors have suggested the possible instability of the passive film after hydrogen peroxide treatment. ${ }^{23}$ This possibility could explain the different surface condition of the samples after toothbrushing with REM; the lower $\mathrm{pH}$ necessary to conserve the bleaching agents, such as peroxide, in this toothpaste may affect the passive film and increase the corrosion of $\mathrm{cp}$ $\mathrm{Ti}$ and Ti-5Ta.

Considering that whitening toothpaste is associated with the effects of fluoride and peroxide on titanium surfaces, further studies are necessary to evaluate whether there is greater ion release from the material surface after toothbrushing with whitening toothpastes. The SEM images suggest that the toothpastes have different effects on the titanium surface even though no significant difference was

\section{References}

1. Ohkubo C, Watanabe I, Ford JP, Nakajima H, Hosoi T, Okabe T. The machinability of cast titanium and Ti-6Al-4V. Biomaterials. $2000 \mathrm{Feb}$;21(4):421-8.

2. Lautenschlager EP, Monaghan P. Titanium and titanium alloys as dental materials. Int Dent J. 1993 Jun;43(3):245-53.

3. Prigent H, Pellen-Mussi P, Cathelineau G, Bonnaure-Mallet M. Evaluation of the biocompatibility of titanium-tantalum alloy versus titanium. J Biomed Mater Res. 1998 Feb;39(2):2006.

4. Kobayashi E, Doi H, Yoneyama T, Hamanaka H, Gibson I, Best SM, et al. Influence of aging heat treatment on mechanical properties of biomedical Ti-Zr based ternary alloys containing niobium. J Mater Sci Mater Med. 1998 Nov;9(11):62530 .

5. Zhou YL, Niinomi M, Akahori T, Fukui H, Toda H. Corrosion resistance and biocompatibility of Ti-Ta alloys for biomedical applications. Mater Sci Eng A Struct Mater. 2005 May;398(1-2):28-36.

6. Faria ACL, Rodrigues RCS, Alves Claro APR, Mattos MGC, Ribeiro RF. Wear resistance of experimental titanium alloys for dental applications. J Mech Behav Biomed Mater. 2011 Nov;4(8):1873-9.

7. Siirilä HS, Könönen M. The effect of oral topical fluorides on the surface of commercially pure titanium. Int J Oral Maxillofac Implants. 1991 Spring;6(1):50-4.

8. Alves-Rezende MCR, Alves APR, Codaro EN, Dutra CAM. Effect of commercial mouthwashes on the corrosion resistance of Ti-10Mo experimental alloy. J Mater Sci Mater Med. 2007 Jan;18(1):149-54. noted in the evaluated parameters.

\section{Conclusion}

The results suggest that toothpastes, depending on the presence of peroxide in their composition, have different effects on the cp Ti and Ti-5Ta surface. Even though no significant difference was noted in the microhardness and roughness of the surfaces brushed with different toothpastes, both toothpastes increased roughness after toothbrushing.

\section{Acknowledgments}

The authors thank FAPESP (\#2010/07312-0) for financial support and Mrs. Ana Paula Rosifini Alves Claro, Mr. Luiz Sérgio Soares, Mrs. Ana Paula Macedo and Mrs. Ana Cristina Morselli Polizello for their technical support.

9. Hossain A, Okawa S, Miyakawa O. Effect of toothbrushing on titanium surface: an approach to understanding surface properties of brushed titanium. Dent Mater. 2006 Apr;22(4):34652.

10. Hossain A, Okawa S, Miyakawa O. Surface texture and composition of titanium brushed with toothpaste slurries of different pHs. Dent Mater. 2007 Feb;23(2):186-92.

11. Nogues LI, Martinez-Gomis J, Molina C, Peraire M, Salsench J, Sevilla $\mathrm{P}$, et al. Dental casting alloys behavior during power toothbrushing with toothpastes with various abrasivities. Part 1: wear behavior. J Mater Sci Mater Med. 2008 Sep;19(9):3041-8.

12. Wiegand A, Kuhn M, Sener B, Roos M, Attin T. Abrasion of eroded dentin caused by toothpaste slurries of different abrasivity and toothbrushes of different filament diameter. J Dent. 2009 Jun;37(6):480-4.

13. Türker SB, Biskin T. The effect of bleaching agents on the microhardness of dental aesthetic restorative materials. J Oral Rehabil. 2002 Jul;29(7):657-61.

14. Türker SB, Biskin T. Effect of three bleaching agents on the surface properties of three different esthetic restorative materials. J Prosthet Dent. 2003 May; 89(5): 466-73.

15. Attin T, Hannig C, Wiegand A, Attin R. Effect of bleaching on restorative materials and restorations - a systematic review. Dent Mater. 2004 Nov;20(9):852-61.

16. Antonini B, Santos CB, Veloso KPM, Marchi GM, Rodrigues JA, Amaral CM. Efeito da escovação com dentifrícios clareadores na rugosidade superficial do esmalte e da dentina. Rev Odontol UNESP. 2007;36:121-6. 
17. Wataha JC, Lockwood PE, Noda M, Nelson SK, Mettenburg DJ. Effect of toothbrushing on the toxicity of casting alloys. J Prosthet Dent. 2002 Jan;87(1):94-8.

18. Schall R. Estimation in generalized linear models with random effects. Biometrika. 1991;78:719-27.

19. Nakagawa M, Matsuya S, Udoh K. Corrosion behavior of pure titanium and titanium alloys in fluoride containing solutions. Dent Mater J. 2001 Dec;20(4):305-14.

20. Khan MA, Williams RL, Williams DF. In vitro corrosion and wear of titanium alloys in the biological environment. Biomaterials. 1996 Nov;17(22):2117-26.
21. Joiner A, Philpotts CJ, Ashcroft AT, Laucello M, Salvaderi A. In vitro cleaning, abrasion and fluoride efficacy of a new silica based whitening toothpaste containing blue covarine. J Dent. 2008;36(Suppl 1):S32-7.

22. Ahn HJ, Song KB, Lee YE, Lee JT, Cho SA, Kim KH. Surface change of dental amalgam after treatment with $10 \%$ carbamide peroxide. Dent Mater J. 2006 Jun;25(2):303-8.

23. Tamam E, Aydin AK. Surface characterization of passive film and elemental release analysis of a Ni-Cr alloy during bleaching, part I: effects of different bleaching agents. Clin Oral Invest. 2011 Jun;15(3):375-82. 